\title{
IMPACTOS AMBIENTAIS URBANOS: O EXEMPLO DO BAIRRO DA VILA CANÁRIA - SALVADOR-BA
}

\author{
Cleidson Gomes Oliveira ${ }^{(a)}$, Dante Severo Giudice ${ }^{(b)}$ \\ (a) Universidade Católica do Salvador-UCSal/ Geógrafo Pós-Graduando em Gestão e Auditoria Ambiental pela \\ Escola de Engenharia Eletro-Mecânica da Bahia-EEEMBA. cleidsongeohumanas@ gmail.com \\ (b) Universidade Católica do Salvador-UCSal/Prof. Dr. do IFCH/UCSal. \\ Dr. em Geografia pela UFS/Geólogo Senior da CBPM dasegu@gmail.com
}

\section{Eixo: GEOGRAFIA FÍSICA E DESASTRES NATURAIS}

\begin{abstract}
RESUMO
O presente trabalho tem como objetivo analisar as implicações de crescimento desordenado em áreas periféricas de Salvador mais especificamente no bairro de Vila Canária. No decorrer da pesquisa foi observado que a população se aglomera em áreas de risco, construindo suas habitações de forma desordenada em áreas de encosta, acentuando a possibilidade de deslizamento. $\mathrm{O}$ descarte do lixo e a falta de esgotamento sanitário também são fatores condicionantes que contribuem para o agravamento dos impactos ambientais na área. A pesquisa realizada no bairro em questão, traz informações relevantes sobre a situação atual, dando suporte aos órgãos competentes para tomada de medidas específicas a fim de minimizar os impactos ambientais na área, assim propiciando melhores condições de qualidade de vida para a população.
\end{abstract}

Palavras chave: Expansão Urbana, Ocupação Espontânea, Impactos Ambientais.

\begin{abstract}
The present work aims to analyze the implications of disordered growth in peripheral areas of Salvador, specifically in the neighborhood of Vila Canara. In the course of the research it was observed that the population congregates in risky areas, constructing their houses in a disorderly way in hillside areas, accentuating the possibility of landslide. The disposal of garbage and the lack of sanitary sewage are also conditioning factors that contribute to the aggravation of environmental impacts in the area. The research carried out in the neighborhood in question brings relevant information about the current situation, supporting the competent bodies to take specific measures in order to minimize the environmental impacts in the area, thus providing better conditions of quality of life for the population.
\end{abstract}

Key-words: Urban Expansion, Occupation Spontaneous, Enviromental Impacts.

\section{INTRODUÇÃO}

O processo acelerado da expansão urbana de Salvador a partir da década de 1950, e a escassez de terrenos públicos, dificultou o acesso da população de baixa renda, impulsionando-as para áreas periféricas (SILVA, 1991). Por consequência da ocupação desordenada, grande parte da população vive em áreas de risco devido à ineficiência das políticas públicas, o que leva ao agravamento da questão da moradia, saneamento, saúde, segurança e consequentemente os impactos ambientais. 
O desenvolvimento desse estudo tem por finalidade transmitir informações de pesquisa acadêmica, e dar subsídios aos setores competentes locais para adoção de medidas específicas, que possibilitem mitigar os impactos ambientais, aos quais se encontra submetido o bairro de Vila Canária localizado na cidade de Salvador, Estado da Bahia.

\section{CARACTERIZAÇÃO DA ÁREA DE ESTUDO}

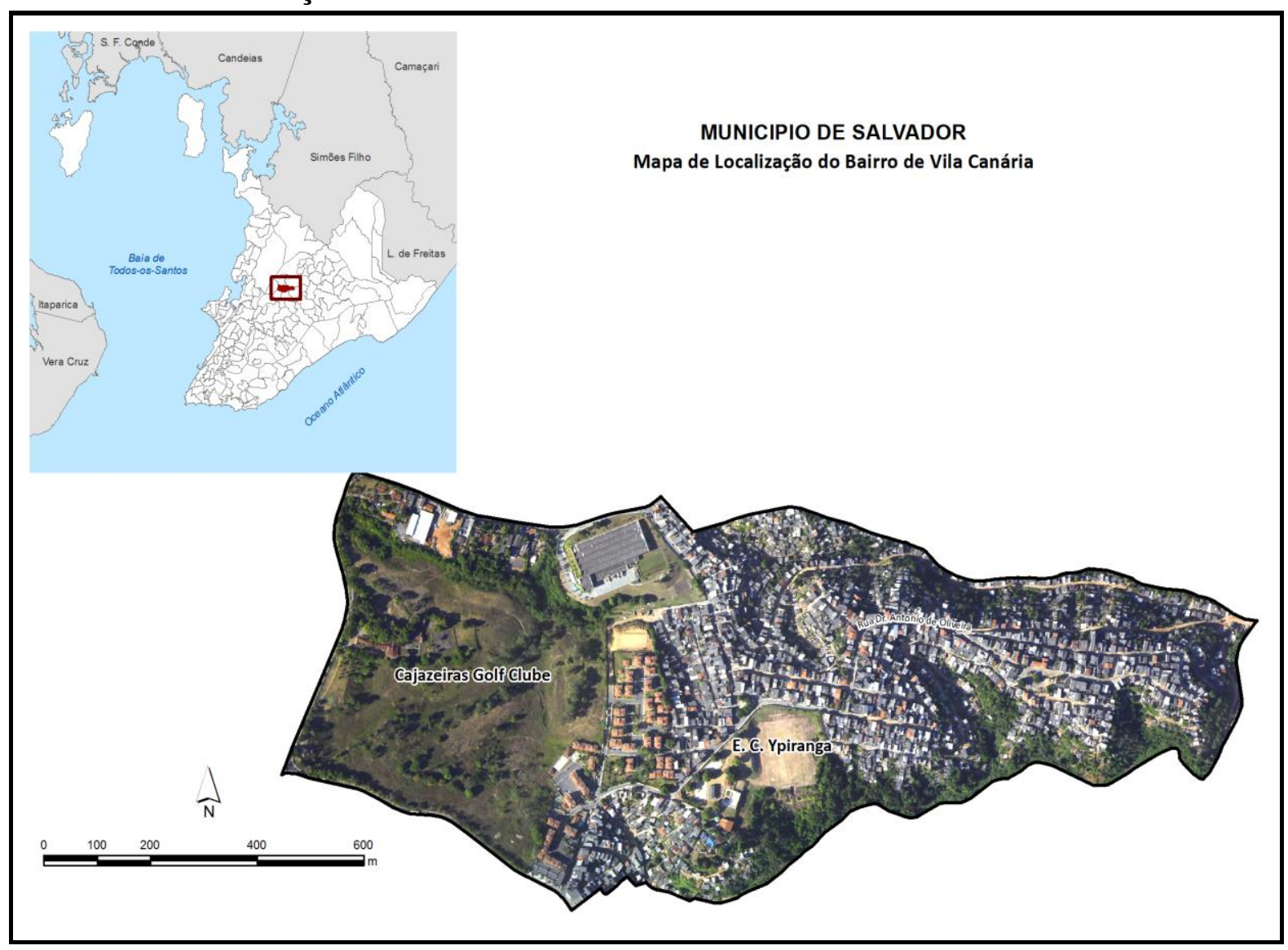

Figura 1 - Localidade do bairro de Vila Canária/Elaborado pelo autor

No local de estudo existem diversas áreas com ocupação espontânea em encostas, onde aparentemente os loteamentos "ilegais" começaram a ocupar os terrenos íngremes ainda livres promovendo a modificação da forma original, e quebrando o seu equilíbrio natural com os cortes dos morros para execução de aterros, onde serão edificadas as moradias que terão ao fundo, taludes artificiais, em geral, bastante íngremes. Estas construções na maioria das vezes não têm o acompanhamento de um profissional capacitado para poder orientá-los de forma adequada, o que termina se constituindo uma área de risco muito vulnerável, sobretudo em época de chuvas. As encostas no bairro de Vila Canária enquadram-se nestas definições segundo o Plano Diretor de Encostas (PDE, 2004). 
Vila Canária é um bairro "bucólico" situado ao Norte na periferia da cidade de Salvador-BA. Este bairro era uma fazenda até meado dos anos 1970, quando passou a ser loteado, vindo a se tornar o bairro que é hoje. Segundo informações do setor de (INFORMS) da Companhia de Desenvolvimento Urbano do Estado da Bahia CONDER (2012), baseando-se no censo demográfico do IBGE (2010), o bairro da Vila Canária possui uma densidade demográfica de 125,05 hab. $/ \mathrm{km}^{2}$ com uma população total de 11.218 habitantes.

O local de estudo possui uma área territorial de $0,90 \mathrm{~km}^{2}$, tendo o relevo na sua quase totalidade constituído por áreas acidentadas, que são cortados por vales encaixados entre morros de aproximadamente 60 metros de altura com topos a meia laranja, formados há milhares de anos pela ação das intempéries da natureza e modificado pela ação antrópica. Nos limites Norte e Sul do bairro de Vila Canária encontram-se os Rios Ypiranga e Cambona que na década de 1980 serviam como recursos hidricos para suprir as necessidades básicas da população local.

A localidade do bairro de Vila Canária pertence ao subdistrito de Pirajá. Subdistrito, são as Unidades Administrativas Municipais, normalmente estabelecidas nas grandes cidades, criadas através de Leis Ordinárias das Câmaras Municipais e sancionadas pelos prefeitos. Os subdistritos de Salvador que totalizam 22 foram criados pela Lei Municipal $\mathrm{n}^{\circ} .1038$ de 15 de junho de 1960, sendo este, o último ano de delimitação de bairro no total de 32 bairros em Salvador. Durante esse espaço de tempo a cidade se expandiu muito surgindo dentro dos subdistritos, as "RAs" e nenhum bairro foi oficialmente criado, totalizando hoje, 160 bairros e 3 ilhas, dificultando assim a delimitação.

O bairro de Vila Canária limita-se com os bairros de Porto Seco Pirajá, Dom Avelar, Castelo Branco, Sete de Abril, Pau da Lima e Jardim Cajazeiras.

\section{A DINÂMICA DA OCUPAÇÃO DO ESPAÇO URBANO}

A dinâmica da ocupação do espaço urbano funciona de acordo com a complexidade, organização e especificidade socioespacial dos diversos lugares em diferentes escalas. O processo responsável pela organização espacial complexa caracteriza as metrópoles, que funcionam como centros de gestão econômica e territorial. As atividades exercidas nesses centros urbanos desempenham um papel fundamental na estrutura espacial, articuladas e organizadas que possui capacidade de integração e também de provocar impacto ao ambiente, conflitos entre o capital e as relações de trabalho.

A questão urbana relacionada à problemática do crescimento desordenado é um tema que há muito tempo vem preocupando estudiosos da área de Urbanismo, das Ciências Geográficas, e também de outras 
Ciências a exemplo das Sociais, Econômicas, dentre outras. Isso se reflete na questão habitacional, relacionadas diretamente aos meios de produção e a renda da população.

Segundo Spósito (2004):

O processo de urbanização no mundo contemporâneo, expressão da acentuação dos papéis urbanos sob o industrialismo e o de novas formas de produção e consumo na cidade, tem provocado o aprofundamento das contradições entre o ambiental e o social nos espaços urbanos.

Souza e Santos (1986), afirmam:

A habitação se transformou no capitalismo, em mercadoria como outra qualquer e, como tal, sua oferta passou a depender da existência de uma demanda efetiva. Dada essa condição, apenas aqueles que podem pagar o seu preço, são os que terão acesso a uma boa moradia.

Por outro lado, as áreas urbanas são constituídas de dois espaços: o "estruturado e o espontâneo" que são diferentes e ao mesmo tempo se completam e são necessários para esse modo de relação: dominação (vs) subordinação. A ação do Estado torna-se indispensável para definir políticas de base estrutural de organização, assumindo uma postura de implementação da ordem no uso do solo, a fim de promover um equilíbrio social, econômico e espacial entre as diferentes classes.

Convém ressaltar que o processo de periferização está vinculado à própria dinâmica de um sistema econômico, político e social. Quanto ao acesso à moradia, há uma relação direta com o salário, a distribuição de renda e a pobreza urbana que diversifica as áreas residenciais.

Em se tratando de moradia, o Estado realiza programas habitacionais voltados para favorecer trabalhadores de baixa renda em locais distantes dos centros urbanos. Entretanto, devido ao crescimento acelerado da população, quantitativamente as unidades são insuficientes para suprir a demanda; e a questão se agrava mais para os trabalhadores que não possuem renda fixa, pois são excluídos do programa. Assim constroem suas casas ou barracos nas encostas de forma irregular, desordenada, sem nenhuma infraestrutura, comum nas grandes cidades.

Segundo Corrêa (1989):

É na produção da favela, em terrenos públicos ou privados invadidos, que os grupos sociais excluídos tornam-se, efetivamente, agentes modeladores, produzindo seu próprio espaço (...) uma forma de resistência, ao mesmo tempo, uma estratégia de sobrevivência, impostas aos grupos sociais recém expulsos do campo ou provenientes de áreas urbanas submetida às operações de renovação que lutam pelo direito à cidade.

Essa questão é a realidade de grande parte da população de baixa renda, pois, com o alto índice de desemprego e um mercado cada vez mais exigente de escolaridade e experiência em carteira de trabalho, resta para uma grande parcela da população, garantir o sustento familiar através do trabalho informal, o 
que não lhe dá condições de se inserir nos programas habitacionais, levando a proliferação de ocupações espontâneas.

\section{EVOLUÇÃO URBANA DE SALVADOR}

Salvador capital do Estado da Bahia, a mais antigas do Brasil; desde o período colonial passou por vários processos evolutivos. A ocupação do solo em Salvador destinado para habitação até a $1^{\text {a }}$ metade do século passado estende-se, sobretudo, ao longo da orla da Baía de Todos os Santos, próximo ao centro da cidade, devido à facilidade dos serviços oferecidos, e a rede viária (SILVA, 1991).

Segundo Giudice (1999), as indústrias foram atraídas pelos incentivos fiscais, adotado pelo governo brasileiro, incentivando o êxodo rural e crescendo um exército de reserva que é necessário à industrialização, muito embora essas novas oportunidades de trabalho tenham sido incapazes, por si só, de absorver produtivamente esse contingente, por não ter qualificação profissional necessária.

A implantação da Petrobras na década de 1950, iniciando a extração e refino de petróleo, instalação do Centro Industrial de Aratu (CIA) na década de 1960, e o funcionamento das primeiras fábricas do Complexo Petroquímico de Camaçari (COPEC) na década de 1970 intensificam consideravelmente a urbanização provocando mudanças estruturais dentre eles o deslocamento do eixo dinâmico da economia do setor agrícola para o industrial.

Em busca de melhoria da qualidade de vida um grande contingente populacional migra do interior e também de outros Estados para Salvador e Região Metropolitana.

Também pela construção do Centro Administrativo da Bahia, da Rodoviária; shoppings centers foram criados, ou surgiram polos que originaram corredores de ocupação que foram rapidamente integrados ao tecido urbano intensificando a expansão da cidade.

Apesar dos investimentos governamentais para a expansão econômica da capital baiana, os migrantes em sua maioria não eram qualificados para exercerem as funções do segundo setor, contribuindo assim para os contrastes socioespaciais: acentuada expansão periférica, problemas habitacionais, tornando insuficientes os serviços públicos, e causando grandes impactos ambientais em função de um planejamento inadequado, ou mesmo da falta dele.

Na década de 1930, com o desenvolvimento da cidade, também aumenta o número de habitantes e, já se começa a pensar em reurbanização a partir de 1935. O desenvolvimento urbano trouxe não só benefícios para a população, mas também muitos transtornos como: um precário sistema de transporte público e a falta de moradias para a população crescente. 


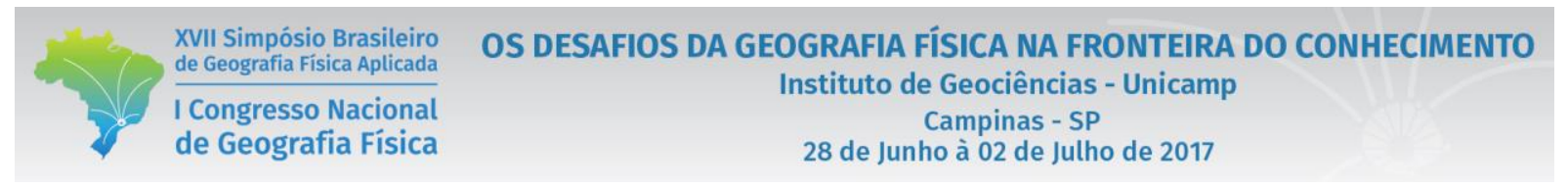

No início da década de 1960, Salvador já contabilizava cerca de 650.000 habitantes, e um dado curioso, é que nessa época, só 30\% da área total do município era ocupada. Em 1967, a capital já totalizava cerca de 900.000 habitantes, mas a infraestrutura não acompanhava o crescimento populacional, evidenciando que precisava se expandir para comportar essa crescente população, e oferecer uma boa infraestrutura (CRUZ \& ARIZE, 2011).

A figura 3 do gráfico, mostra o crescimento da população de Salvador, entre 1960 e 2010, com acréscimo de cerca de meio milhão de habitantes por década. Entretanto, dados estimativos do IBGE (2010), mostram que o crescimento caiu bastante, atingindo $0,69 \%$ no ano de referência. Isso pode ser reflexo tanto da migração e da natalidade, como também de transferência da população para outros municípios da área metropolitana, como Lauro de Freitas e (Camaçari/orla), sobretudo na busca por melhores condições de vida.

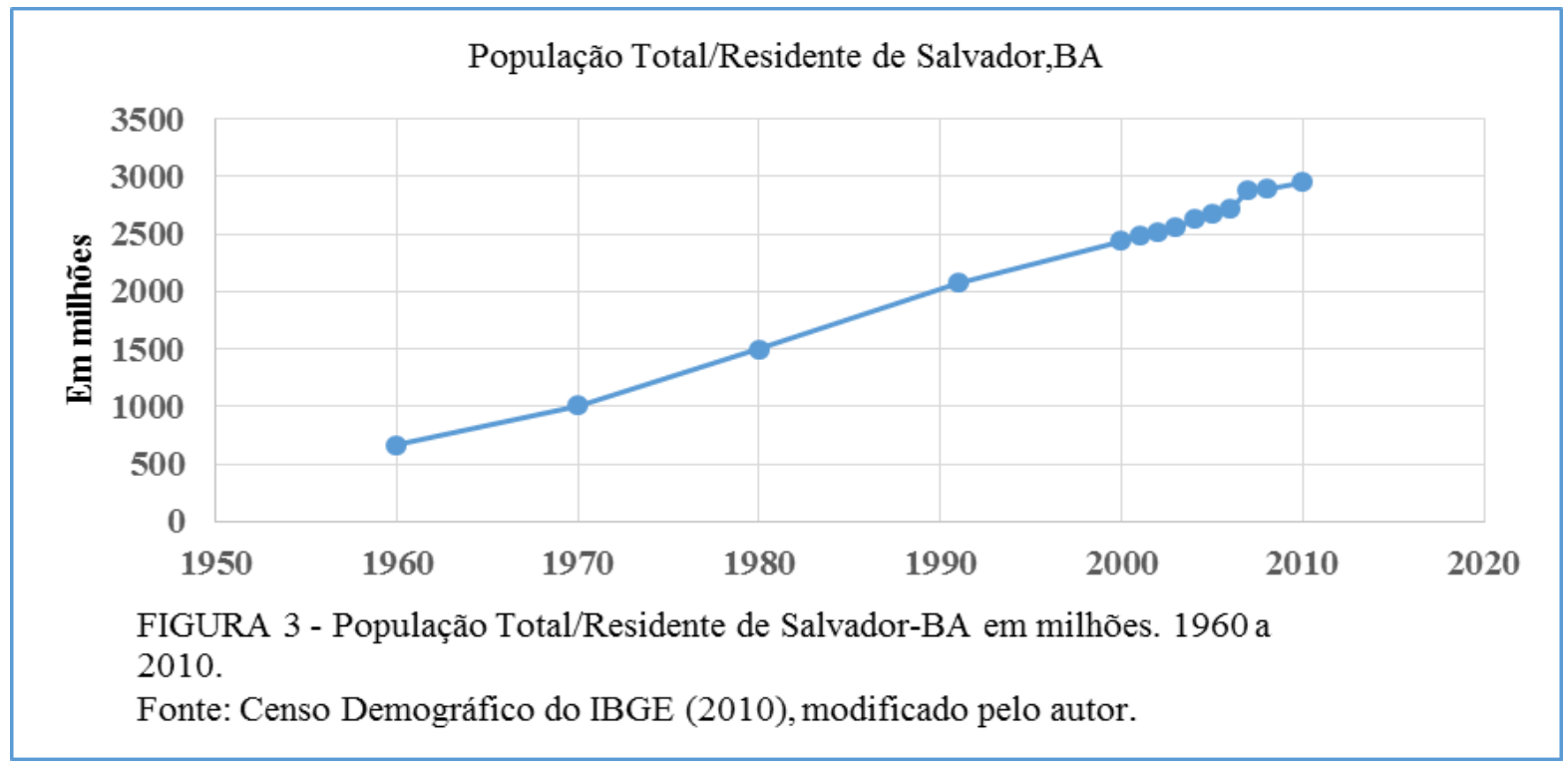

\section{RESULTADOS E DISCUSSÕES}

\subsection{Distribuição pluviométrica de Salvador}

Atuando sobre o modelado tema na cidade, um clima tropical úmido, onde as estações do ano quase não têm definição climática especifica pelo fato de chover quase o ano inteiro. As temperaturas médias são praticamente constantes o ano todo, mas num verão quente, pode atingir até $38^{\circ} \mathrm{C}$ e inverno com temperaturas mínimas de até $17^{\circ} \mathrm{C}$. Os meses do ano menos chuvosos são janeiro, setembro e dezembro, 


\section{OS DESAFIOS DA GEOGRAFIA FÍSICA NA FRONTEIRA DO CONHECIMENTO \\ Instituto de Geociências - Unicamp \\ Campinas - SP \\ 28 de Junho à 02 de Julho de 2017}

com uma precipitação média de $(63,1 \mathrm{~mm} / \mathrm{mês})$, como mostra a tabela $\mathrm{I}$, tendo o mês de dezembro de 2009 no quadro verde, como o mês com menor precipitação em relação aos anos estudados.

Em contrapartida, os meses de maiores intensidades de chuvas são: abril, maio e junho, com média de (286,6 mm/mês) nos últimos nove anos de monitoramento pluviométrico pelo INMET.

Consta-se que 2004, 2005, 2006 e 2011, foram os anos que mais choveu na capital baiana, com médias de (2.321,3 mm/ano), e um acumulado total de (16. 618,1 $\mathrm{mm}$ de chuvas de 2004 até 2013). A linha em preto sinalizada com um xis (X), sem dados estatísticos, indica que a tabela de dados cedida pela fonte pesquisada, ainda não havia fechado seus levantamentos anuais até o termino da nossa pesquisa.

Tabela I - Índice pluviométrico em (mm) dos últimos dez anos, (vs) média mensal, (vs) total por ano.

\begin{tabular}{c|c|c|c|c|c|c|c|c|c|c|c|c|c}
\hline $\begin{array}{c}\text { Mês } \\
\text { Ano }\end{array}$ & Jan & Fev & Mar & Abr & Mai & Jun & Jul & Ago & Set & Out & Nov & Dez & $\begin{array}{c}\text { Acumulo } \\
\text { Total }\end{array}$ \\
\hline 2004 & 319,4 & 165,3 & 122,3 & 278,4 & 158,3 & 327,0 & 218,4 & 129,5 & 40,0 & 82,0 & 167,6 & 10,8 & $2.019,0$ \\
\hline 2005 & 42,9 & 349,4 & 349,4 & 415,0 & 198,2 & 421,1 & 204,1 & 117,1 & 50,6 & 32,9 & 72,8 & 75,5 & $2.329,0$ \\
\hline 2006 & 40,1 & 7,1 & 35,0 & 587,4 & 397,1 & 401,4 & 91,7 & 117,7 & 126,9 & 258,9 & 220.0 & 30,3 & $2.313,6$ \\
\hline 2007 & 20,0 & 282,6 & 86,8 & 139,8 & 211,2 & 134,0 & 130,0 & 109,0 & 86,7 & 78,9 & 19,1 & 18,8 & $1.317,3$ \\
\hline 2008 & 17,8 & 182,6 & 132,8 & 154,3 & 203,6 & 178,2 & 148,8 & 58,7 & 37,8 & 31,7 & 78,4 & 103,5 & $1.328,2$ \\
\hline 2009 & 30,3 & 122,1 & 25,6 & 506,6 & 549,3 & 155,1 & 158,9 & 93,8 & 56,1 & 162,4 & 48,1 & 5,8 & $1.914,1$ \\
\hline 2010 & 78,3 & 19,2 & 122,8 & 448,8 & 243,8 & 96,7 & 492,5 & 176,3 & 56,8 & 56,7 & 22,6 & 102,2 & $1.916,7$ \\
\hline 2011 & 170,3 & 46,2 & 200,7 & 331,0 & 304,2 & 277,7 & 57,3 & 91,3 & 62,0 & 208,5 & 319,2 & 86,4 & $2.154,8$ \\
\hline 2012 & 35,7 & 70,9 & 74,4 & 48,9 & 411,5 & 168,3 & 162,5 & 137,4 & 30,7 & 73,6 & 35,5 & 10.3 & $1.260,4$ \\
\hline 2013 & 36,2 & 28,8 & $\mathrm{X}$ & $\mathrm{X}$ & $\mathrm{X}$ & $\mathrm{X}$ & $\mathrm{X}$ & $\mathrm{X}$ & $\mathrm{X}$ & $\mathrm{X}$ & $\mathrm{X}$ & $\mathrm{X}$ & 65,0 \\
\hline Média & & & & & & & & & & & & & \\
mensal & 79,1 & 127,4 & 127,8 & 322,4 & 297,5 & 239,9 & 184,9 & 114,5 & 60,8 & 109,5 & 109,3 & 49,3 & $16.618,1$ \\
\hline
\end{tabular}

FONTE: INMET, (2004 a 2013), Coordenadoria de Defesa Civil, Codesal, (2013). Elaborado pelo autor, (2013).

Para elaboração da pesquisa num primeiro momento, foi feito o levantamento das ocorrências sobre os tipos de riscos geológicos em áreas de encostas causados por moradias irregulares. Esse levantamento foi feito por uma equipe de profissionais de engenharia e técnicos da Coordenadoria de Defesa Civil de Salvador (CODESAL), em parceria com outros órgãos da prefeitura de Salvador. Esses registros foram catalogados no período de 01/01/2004 à 06/02/2013, depois que o Sistema de Informação foi implantado por esta secretaria.

Durante esse período, foram feitos levantamentos em 66 localidades diferentes, entre eles; avenidas, ruas e travessas do bairro, sendo detectados na área, nesses nove anos, 14 tipos de diferentes situações, tais como: (alagamento de área, ameaça de desabamento de muro, ameaça de desabamento, ameaça de deslizamento, árvore ameaçando cair, árvore caída, avaliação de área, avaliação de imóvel alagado, 
desabamento de imóvel, desabamento de muro, desabamento parcial, deslizamento de terra, infiltração, além de orientação técnica), totalizando 613 ocorrências como é mostrado na tabela.

Tabela II - Dos acidentes ocorridos no período de 01/01/2004 a 06/02/2013

\begin{tabular}{l|c|c|r|r|r|r}
\hline Quantidades e tipos de acidentes & $\begin{array}{l}\text { Grau de } \\
\text { risco/sem } \\
\text { risco }\end{array}$ & $\begin{array}{l}\text { Grau de } \\
\text { risco/baixo }\end{array}$ & $\begin{array}{l}\text { Grau de } \\
\text { risco/médio }\end{array}$ & $\begin{array}{l}\text { Grau de } \\
\text { risco/Alto }\end{array}$ & $\begin{array}{l}\text { Grau de } \\
\text { risco/muito } \\
\text { alto }\end{array}$ \\
\hline Alagamento de área & 21 & 0 & 4 & 6 & 9 & 2 \\
\hline Ameaça de desabamento de muro & 6 & 0 & 0 & 3 & 3 & 0 \\
\hline Ameaça de desabamento & 110 & 1 & 3 & 28 & 39 & 40 \\
\hline Ameaça de deslizamento & 195 & 0 & 12 & 78 & 87 & 18 \\
\hline Árvore ameaçando cair & 7 & 0 & 1 & 3 & 1 & 2 \\
\hline Árvore caída & 3 & 0 & 0 & 1 & 0 & 2 \\
\hline Avaliação de área & 7 & 2 & 2 & 2 & 1 & 0 \\
\hline Avaliação de imóvel alagado & 1 & 0 & 1 & 0 & 0 & 0 \\
\hline Desabamento de imóvel & 40 & 1 & 1 & 7 & 12 & 19 \\
\hline Desabamento de muro & 8 & 0 & 2 & 2 & 4 & 0 \\
\hline Desabamento parcial & 4 & 0 & 0 & 0 & 3 & 1 \\
\hline Deslizamento de terra & 152 & 2 & 2 & 56 & 61 & 32 \\
\hline Infiltração & 3 & 0 & 1 & 2 & 0 & 0 \\
\hline Orientação Técnica & 56 & 9 & 24 & 18 & 4 & 2 \\
\hline Total & 613 & 14 & 53 & 206 & 224 & 118 \\
\hline
\end{tabular}

FONTE: Coordenadoria de Defesa Civil/SSA, CODESAL (2013), Elaborado pelo autor (2013).

Muitos desses problemas ainda perduram até os dias atuais e continuam sem solução por parte dos órgãos públicos, como pode ser visto nas figuras 04 e 05 , a própria população tenta buscar soluções por iniciativa própria para amenizar a situação precária onde vivem como pontes improvisadas, canalização de esgoto residencial feito de forma inadequada e rede de esgoto comunitária sem manilhas correndo a céu aberto.
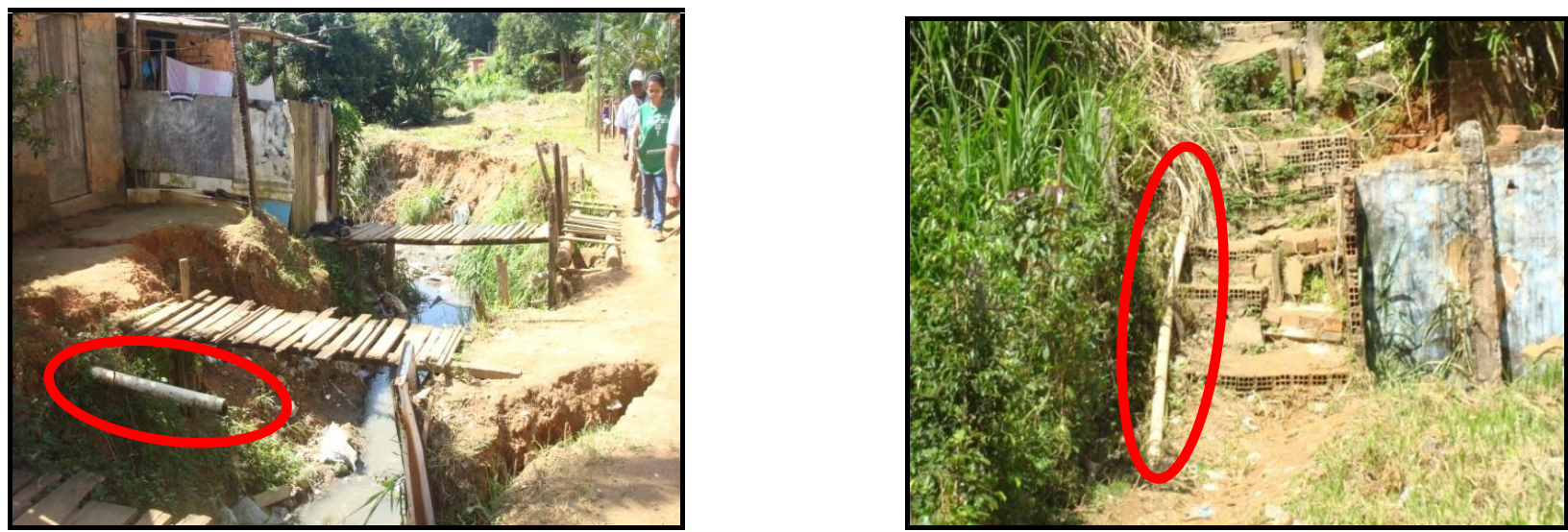

FIGURAS 04/05 - Canalização de esgoto. /FONTE: Coordenadoria Defesa Civil, (CODESAL, 2010).

Os moradores locais também têm sua parcela de culpa pela situação em que se encontram, pois, uma parte dela insiste em descartar o lixo e os entulhos nas encostas, que muitas vezes vão parar nas bocas de lobo (figuras 06 e 07). 

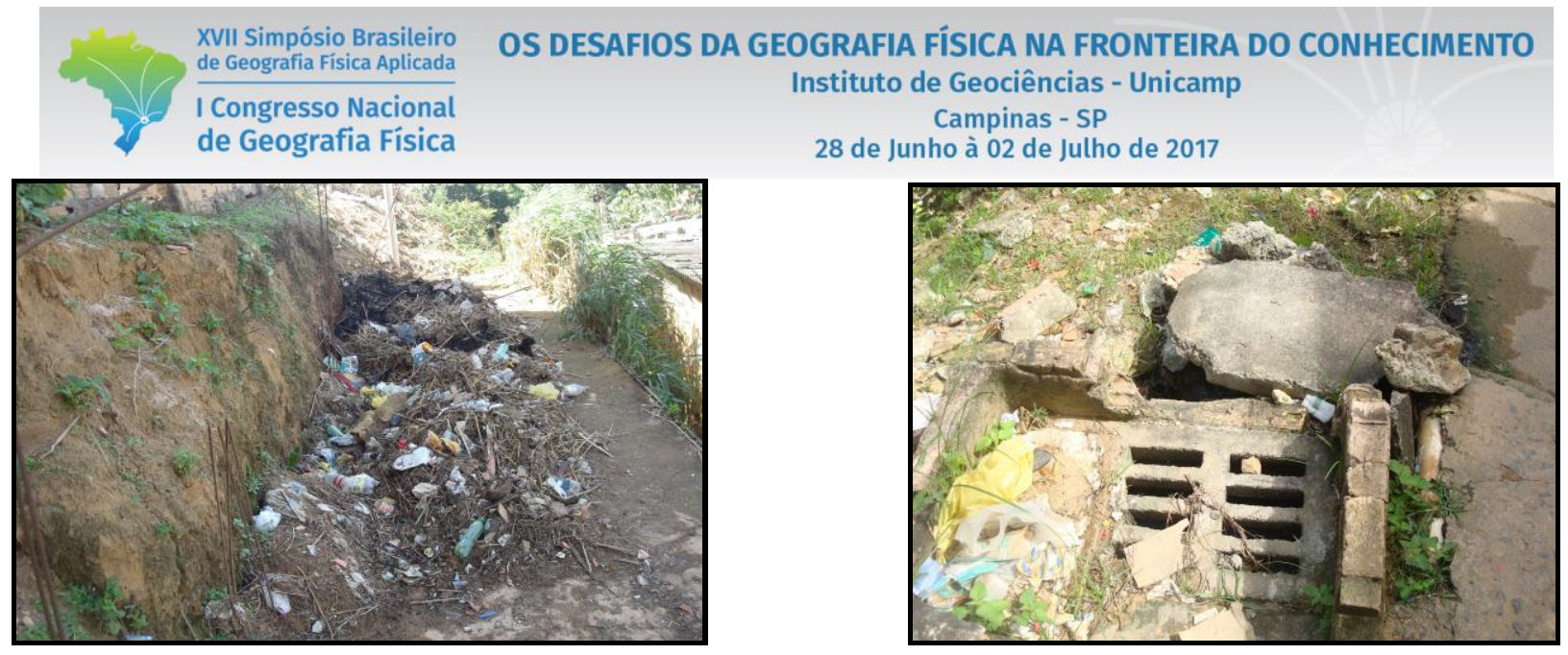

FIGURAS 06/07 - Descarte de lixo. /FONTE: Coordenadoria Defesa Civil, (CODESAL, 2010).

A tabela III, mostra os tipos de moradias, profissões dos moradores e o tempo de residência das pessoas em porcentagens. Quanto às moradias, apesar de ser uma área de instabilidades, e sem muito valor agregado, 92,3\% das construções são de alvenaria; apenas 7,7\% corresponde a barracos de madeira e não houve registro de construções feitas de "taipa ou pau a pique".

$\mathrm{Na}$ questão profissional dos moradores dessas áreas, o que era de se esperar, é que uma grande parcela desses moradores estivesse atuando no mercado informal, mas o que se constatou foi o inverso; $53,8 \%$ dessa mão de obra estão trabalhando na formalidade com profissões diversas, como - motoristas, comerciários, comerciantes, professores, operadores de maquinas, funcionários públicos, recepcionistas e estudantes. Esta porcentagem de 7,7\% que corresponde aos estudantes foram pessoas entrevistadas com idade superior a dezoito anos que ainda não tinham uma profissão formal e se declararam como tal.

Quanto ao tempo de moradia, às pessoas têm um tempo significativo de residência; 69,2\% dos moradores dizem ter mais de quinze anos, 15,4\% com mais de dez anos e 15,4 com menos de quatro anos de residência no bairro.

A tabela III evidencia que a grande demanda por habitação se deve a migração entre o interior e a capital (aqui conhecido como campo-capital), e essa pressa por espaço, leva as ocupações por áreas impróprias como as encostas.

No caso em estudo, quase 54\% dos moradores são advindos do interior e, apesar das dificuldades enfrentadas, mais de $92 \%$ são proprietários dos imóveis que residem.

Tabela III - Tipos de Moradias/ Profissão/ Tempo de Residência no Local

\begin{tabular}{l|c|l|l|l|c}
\hline \multicolumn{2}{c|}{ Tipos de moradias } & \multicolumn{2}{c}{ Profissões } & \multicolumn{2}{c}{ Tempo de residência local } \\
\hline Alvenaria & $92,3 \%$ & Dona de casa & $38,5 \%$ & Mais de quinze anos & $69,2 \%$ \\
\hline Barraco de madeira & $7,7 \%$ & Estudantes & $7,7 \%$ & Mais de dez anos & $15,4 \%$ \\
\hline Casa de taipa & $0 \%$ & Outras profissões & $53,8 \%$ & Menos de quatro anos & $15,4 \%$ \\
\hline
\end{tabular}

FONTE: Pesquisa de campo elaborada pelo autor, (2013). 
Verificou-se também que o nível escolar das pessoas está muito aquém do que se espera para um desenvolvimento intelectual de uma comunidade, mas é inteiramente compreensível, uma vez que as pessoas deixam a escola para trabalhar e ajudar no sustento das famílias. Como esperado, a tabela 05, a seguir, indica que mais da metade da população; $53,8 \%$ do total cursou apenas o "ensino fundamental I" enquanto, que 30,8\% fizeram o "fundamental II" e, apenas 15,4\% desse universo conseguiu concluir o ensino superior.

Comprovado a nossa premissa de que alguns dos problemas das encostas nos grandes centros urbanos geralmente são advindos da migração de pessoas do interior do estado e de outras regiões para as capitais e áreas instáveis, a tabela 05 , mostra exatamente essa questão da origem das famílias que vêm do interior do estado para a capital atrás de uma vida melhor. Os 53,8\% dos moradores locais, têm sua origem de fora dos grandes centros urbanos. Apesar de todas as dificuldades enfrentadas pelos moradores ao chegar de outras regiões para conseguir uma moradia, mais de $92 \%$ dessas pessoas possuem casa própria ver tabela.

Tabela IV - Escolaridade - origem da família - propriedade da residência

\begin{tabular}{|c|c|c|c|c|c|}
\hline \multicolumn{2}{|l|}{ Escolaridade } & \multicolumn{2}{|c|}{ Origem da família } & \multicolumn{2}{|c|}{ Propriedade da residência } \\
\hline Nível Fundamental I & $53,8 \%$ & Interior do Estado & $53,8 \%$ & Casa Própria & $92,3 \%$ \\
\hline Nível Fundamental II & $30,8 \%$ & Salvador & $46,2 \%$ & Casa Alugada & $7,7 \%$ \\
\hline Nível Superior & & & $5,4 \%$ & & \\
\hline
\end{tabular}

FONTE: Pesquisa de campo elaborada pelo autor, (2013).

\section{IMPACTOS AMBIENTAIS}

\subsection{Impactos Ambientais Urbanos}

O processo de urbanização acelerado é reflexo do capitalismo, dos meios de produção e do desenvolvimento no espaço urbano. Esse processo, que intensificou o ritmo no século XX, tem promovido contradições sociais, transformações do meio físico, causando grandes impactos.

Segundo Carlos e Lemos (2005), a diminuição da cobertura vegetal como condição para a densidade construtiva que caracteriza, e a reivindicação da vegetação, sob forma de paisagismo, como adorno de uma cidade em busca de um passado natural são outras formas de se ver como a produção da cidade se relaciona com as dinâmicas e processos constitutivos da natureza.

Devido ao processo de crescimento das aglomerações urbanas, em consequência da necessidade de intervenção do Estado na política de crescimento econômico das cidades brasileiras, os impactos 
ambientais nas principais metrópoles se intensificam a cada dia, sobretudo com as construções em área de encostas.

\section{IMPACTOS AMBIENTAIS NA ÁREA DE ESTUDO}

Segundo Silva (op. cit. 1991), a "modernização" da cidade não significou uma possibilidade de melhoria das condições de habitação da grande maioria da população. As terras públicas tornam-se também cada vez mais escassas devido à especulação imobiliária que valoriza os imóveis próximos de áreas que possuem equipamento de infraestrutura. Como alternativa para a população de baixa renda, resta habitar áreas cujos terrenos possuem valor mais accessível ou de invasão em áreas de encosta, onde ocorrem com frequência - principalmente em períodos chuvosos - alagamentos e escorregamentos de terra.

Para Giudice (op. cit.1999), as mudanças ambientais resultam das transformações que operam nos sistemas naturais, manifestadas através de desequilíbrios, impactos e degradação de modo geral, e é consequência dos processos socioeconômicos que influenciam na organização espacial, em particular nas áreas urbanas, onde as ações antrópicas mais intensas podem gerar reações adversas à natureza. Portanto, diante da colocação do autor, o processo de urbanização tem causado profundas modificações no meio natural.

É muito comum no bairro topografia acidentada onde predominam terrenos de encosta, e a maioria das construções são irregulares. Não são submetidas à vistoria técnica, e são construídas sem o alvará de construção concedida pela Prefeitura, aumentando o risco para a população que vive em constante ameaça de perder seus imóveis e até mesmo suas vidas.

As ocorrências segundo, a CODESAL, se intensificam mais nos meses que variam de março a junho, período que tradicionalmente ocorrem maior índice pluviométrico,

Outros fatores tais como saneamento deficiente, contribuem para o aumento dos impactos na área, a exemplo da inexistência de esgotamento sanitário e vazamento na rede de água e esgoto; o lixo, é uma preocupação agravante, pois a maioria das residências não é beneficiada com a coleta, tendo que depositar os resíduos em caixas coletoras, mas termina espalhado pelo solo; as fossas sanitárias são outra fonte de infiltração de água no solo, podendo originar a ocorrência de escorregamentos, devido à saturação gradual do solo na encosta, existem inúmeras fossas que devido à declividade das encostas muitas vezes estão coladas as paredes das casas, o que torna a situação mais crítica, pois além de influenciar na saturação do solo, pode acarretar problemas de saúde pública, e de instabilidade das mesmas, já que são construídas de forma precária. 
Estas constatações evidenciam um problema de saúde pública, pois diversos casos das doenças que foram constatadas na população local estão relacionados à baixa situação socioeconômica em que se encontra a população do bairro.

\section{CONSIDERAÇÕES FINAIS}

Assim, com base na análise de todos os problemas, e na sintetização das informações obtidas através dos questionários aplicados, os efeitos da ação antrópica no meio ambiente são altamente significativos, e no caso específico da Vila Canária, alcança grande dimensão, motivo pelo qual se procura buscar soluções que levem a um maior equilíbrio do meio ambiente e consequentemente traga melhorias nas condições de vida da população envolvida. Segundo Ogata (op. cit. 1983), esse tipo de problema, em ambiente urbano, enquadra-se no nível etnológico-psicológico, principalmente em locais de ocupação espontânea de baixa renda, mais que em qualquer outra parte do espaço urbano, formando condições para o desenvolvimento comportamentais ativos. No entanto, a população local, tem uma visão crítica dos seus problemas, percebendo-os e procurando solucioná-los da melhor forma possível.

\section{BIBLIOGRAFIA}

BRASIL, INSTITUTO BRASILEIRO DE GEOGRAFIA E ESTATÍSTICA - IBGE. Censos demográficos 1970, 1980, 1991, 2000, 2010.

CARLOS, Ana Fani Alessandri; LEMOS Amélia Inês Geraïges. Dilemas Urbanos: Novas Abordagens sobre a Cidade. $2^{a}$ ed. São Paulo: Contexto, 2005.

CONDER, Informes, Sedir, 2012. Características Demográficas dos Bairros do Município de Salvador-BA. IBGE, 2010.

COODENADORIA DE DEFESA CIVIL DE SALVADOR - CODESAL. Setor de Estudos e Projetos. CORRÊA, Roberto Lobato. O Espaço Urbano. Editora Ática S.A. São Paulo, 1989.

CRUZ, Fernanda; ARIZE, Juliana. Salvador e seu Processo de Urbanização, 1970. Disponível em: < http://www.recantodasletras.com.br/artigos/1970488 > acesso em: 12/03/2013.

GIUDICE, Dante Severo. Impactos Ambientais em área de ocupação espontânea: (exemplo do bairro do Calabar, Salvador-BA). Salvador, 1999. Dissertação de Mestrado.

IBGE. Instituto Brasileiro de Geografia e Estatística. Censo 2010: População do Brasil é de 190.732.694 pessoas. Disponível em: 〈http://www.ibge.gov.br/home/presidencia/noticias/noticia_visualiza.php?id_noticia=1766 >acesso em 15/02/2013.

OGATA, M. G. Os resíduos sólidos na organização do espaço e na qualidade do ambiente urbano: uma contribuição geográfica ao estudo do problema na cidade de São Paulo. Rio de Janeiro: IBGE, 1983.

SALVADOR. Plano Diretor de Encostas do Município de Salvador. Relatório Síntese. PDE, 2004.

SILVA, S. B. de M.e. Processo de Crescimento Espacial de Salvador. In: Silva, S. B. de M.e.; Silva, B. C. N. Cidade e Região no Estado da Bahia. Salvador: Centro Editorial e Didático da UFBA, 1991.

SOUZA, Maria Adélia A; SANTOS, Milton. A construção do espaço. São Paulo: Nobel, 1986.

SPÓSITO, Maria Encarnação Beltrão. Capitalismo e Urbanização. São Paulo: Contexto, 2004. 